\title{
Respiratory Distress and Its Outcome among Neonates Admitted to Neonatal Intensive Care Unit of Assiut University Children Hospital, Egypt
}

\author{
Hala H. Abou-Faddan ${ }^{1}$ and Nafisa H.R. Abdelaziz ${ }^{2}$ \\ ${ }^{1}$ Departments of Public Health and Community Medicine and ${ }^{2}$ Pediatrics, Faculty of \\ Medicine, Assuit University, Assuit, Egypt \\ Received: October, 2017 Accepted: December, 2017
}

\begin{abstract}
Objective: To identify proportion and etiology of respiratory distress (RD), its mortalities and associated risk factors among neonates admitted to Neonatal Intensive Care Unit (NICU) of Assiut University Children Hospital. Methods: A cross-sectional study design was carried out. All RD neonates admitted to NICU of Assiut University Children Hospital during the study period were included. Results: Respiratory distress neonates constituted $52.9 \%$ of total admission. Hyaline membrane disease represented $45.8 \%$ of RD cases. The majority of hyaline membrane disease cases (RDS) were preterm and low birth weight $(96.2 \%$ \& 93.7\% $\%$ respectively). The majority of hyaline membrane diseased neonates who were treated by surfactant or Continuous Positive Airway Pressure (CPAP) recovered (75.8\% \& 66.7\% respectively) with significant statistically difference. The most fatal of respiratory distress diseases were persistent pulmonary hypertension (91.2\%). Significant independent factors associated with neonatal mortalities due to respiratory distress were residence, causes of RD, birth weight and place of delivery. Conclusion: Hyaline membrane disease, pneumonia, transient tachypnea of the newborn (TTN), meconium aspiration syndrome (MAS) were important causes of neonatal respiratory distress. Residence, causes of RD, birth weight and place of delivery were significantly associated with respiratory distress mortalities. Recommendation: Development of strategies aiming to reduction of RD among neonates is highly recommended. Moreover, surveillance programs for neonatal mortality should be coupled with preventive measures and interventions for better natal care and postnatal outcome.
\end{abstract}

Key words: respiratory distress, neonate, Neonatal Care Unit, outcome, Assiut University Children Hospital.

Corresponding author : Hala H. Abou-Faddan mail: halaaboufaddan@yahoo.com

\section{Introduction}

The neonatal period (first month of life) conveys the most prominent dangers of death in the human life expectancy. To study neonatal mortality, it is required to know causes of disease, its distribution and transmission cause-of-death and wellbeing intercession. ${ }^{1}$

The causes of early neonatal death (first 24 hours) are different from those that occur later. To improve outcome of interventions programs, it is important to know précised data about timing and causes of death. ${ }^{2}$ The most important cause of neonatal morbidity and mortality is respiratory distress (RD). It commonly occurs in premature babies, with an 
occurrence and seriousness conversely related to gestational age and birth weight. The incidence of RD is $1 \%$ of all births, however increases to $50 \%$ at 30 weeks gestation, $75 \%$ at 28 weeks and $90 \%$ at 26 weeks. $^{3}$

Apnea, cyanosis, inspiratory stridor, snorting nasal flaring, grunting, feeding problem, and tachypnea (over 60 breaths in step with minute) are important signs and symptoms of respiratory distress of neonate. In addition to intercostals and sub costal retractions. Hyaline membrane diseases, transient tachypnea of the neonate (TTN), or meconium aspiration syndrome (MAS) are the most widely recognized reasons for RD. In addition, sever infection as pneumonia, persistent pulmonary hypertension of the newborn, and pneumothorax considered major causes. ${ }^{4}$

In NICU, RD of neonate is significant problem. The important risk factors of $\mathrm{RD}$ are: history of maternal smoking, male sex and elective caesarian delivery. Usage of antenatal corticosteroid drugs and holding up delivery until 39 weeks are significant interventions for decreasing $\mathrm{RD}$ after elective $\mathrm{C} / \mathrm{S}$ at term. ${ }^{5}$

$\mathrm{RD}$ is an important cause of neonatal mortality globally particularly in developing countries. The fundamental interventions of oxygen and continuous positive airway pressure (CPAP) have the best effect on diminishing RD and its mortality globally. ${ }^{6}$

In Egypt, a study of neonatal mortality in intensive care unit in children's hospital, Cairo University revealed that mortality from RD among neonates comprise $26.7 \%$ of all deaths and constitute $9.6 \%$ and one of important causes of admission to the NICU.7

Decrease morbidity and mortality due to RD in Neonatal Intensive Care Unit of Assiut University Children Hospital, Egypt and improve neonatal health is the main goal of this study. Objectives: (1) To identify proportion and etiology of RD among neonates admitted to Neonatal Intensive Care Unit (NICU) of Assiut University Children Hospital. (2) To identify mortalities (case fatalities) from $\mathrm{RD}$ and their associated risk factors among neonates admitted to Neonatal Care Unit of Assiut University Children Hospital.

\section{Methods}

Study population: Neonates admitted to the Neonatal Intensive Care Unit of Assiut University Children Hospital who diagnosed as RD. Study site: Neonatal Intensive Care Unit (NICU) of Assiut University Children Hospital. Study design: cross sectional study. Sampling and sample size: Sample size was calculated using EPI INFO VERSION 7 software. Stat-Calc function. Based on the following criteria: Expected frequency of the studied phenomenon: $19.7 \%^{8}$ at Confidence level $99 \%$. The calculated sample size was 420 neonates, 487 were included in the present study. About 2000 neonates admitted per year into NICU, so monthly admission about 166 neonates about half of admission neonates were diagnosed as $\mathrm{RD}$, in order to yield sample size the study continue for 6month.

Sampling technique: (Total coverage for $\mathrm{RD}$ neonates admitted to the neonatal care unit of Assiut University Children Hospital during the period of the study (6 months) between June 2014 to November 2014.

Data collection: Data was collected from the patient sheet of NICU with more details of the sheet which includes the following:

First part: data of the mother: Personal data as name, age, occupation and consanguinity, Obstetric history: History of stillbirth, abortion and congenital anomalies. History of the present 
Table (2): Relationship between gestational age, birth weight and causes of RD of neonates admitted to NICU of Assiut University Children Hospita, 2014

\begin{tabular}{|c|c|c|c|c|}
\hline \multirow[b]{2}{*}{ Causes of RD } & \multicolumn{2}{|c|}{ Gestational age ( $\%$ from rows) } & \multirow{2}{*}{$\begin{array}{c}\text { Total } \\
(\mathrm{N}=\mathbf{4 8 7})\end{array}$} & \multirow[b]{2}{*}{ P-value } \\
\hline & $\begin{array}{c}\text { Full term (152) } \\
\text { N }(\%)\end{array}$ & $\begin{array}{c}\text { Preterm (335) } \\
\text { N (\%) }\end{array}$ & & \\
\hline Hyaline membrane disease & $11(4.9)$ & $212(96.2)$ & 223 & $<0.0001$ \\
\hline Transient tachypnea of the newborn & $39(47)$ & $44(53.0)$ & 83 & 0.001 \\
\hline Meconium aspiration syndrome & $8(88.9)$ & $1(11.1)$ & 9 & 0.001 \\
\hline Pneumonia & $36(41.9)$ & $50(58.1)$ & 86 & 0.019 \\
\hline Persistent pulmonary hypertension & $18(52.9)$ & $16(47.1)$ & 34 & 0.005 \\
\hline Congenital anomalies* & $40(76.9)$ & $12(23.1)$ & 52 & $<0.0001$ \\
\hline \multirow[b]{2}{*}{ Causes of RD } & \multicolumn{2}{|c|}{ Birth weight (\% from rows) } & \multirow{2}{*}{$\begin{array}{c}\text { Total } \\
(\mathbf{N}=\mathbf{4 8 7})\end{array}$} & \multirow[b]{2}{*}{ P-value } \\
\hline & $\begin{array}{c}\text { Normal (129) } \\
\text { N (\%) }\end{array}$ & $\begin{array}{c}\text { Low (358) } \\
\text { N (\%) }\end{array}$ & & \\
\hline Hyaline membrane disease & $14(6.3)$ & $209(93.7)$ & 223 & $<0.0001$ \\
\hline Transient tachypnea of the newborn & $41(49.4)$ & $42(50.6)$ & 83 & $<0.0001$ \\
\hline Meconium aspiration syndrome & $6(66.7)$ & $3(33.3)$ & 9 & $\square \mathbf{0 . 0 1 3}$ \\
\hline Pneumonia & $25(29.1)$ & $61(70.9)$ & 86 & 0.55 \\
\hline Persistent pulmonary hypertension & $14(41.2)$ & $20(58.8)$ & 34 & 0.04 \\
\hline Congenital anomalies* & $29(55.8)$ & $23(44.2)$ & 52 & $<0.0001$ \\
\hline
\end{tabular}

Chi square $\left(\chi^{2}\right)$ test was used, ${ }^{\square}$ Fisher's exact test. *Congenital anomalies (diaphragmatic hernias, pulmonary hypoplasia., tracheoesophageal fistula, congenital lobar emphysema-- and congenital heart disease)

were females with significant statistically difference.

Table (4): shows that $94.2 \%$ of mothers congenital anomalies neonates and $66.8 \%$ of mothers of hyaline membrane diseased neonates were multigravida with significant statistical difference .Furthermore, $62.8 \%$ of congenital anomalies cases were delivered by Cesarean section with significant statistically difference .

Table (5): shows that majority of hyaline membrane diseased neonates who treated by surfactant or CPAP were recovered (75.8\%\& 66.7\% respectively) with significant statistically difference.

Table (6): shows that the highest case fatality of respiratory distress diseases were persistent pulmonary hypertension (91.2) followed by hyaline membrane disease and congenital anomalies (69.5\% \& 69.2\% respectively). Table (7): shows that hyaline membrane diseased, persistent pulmonary hypertension, congenital anomalies neonates had shorter mean survival time than those did not have $(27.32 \pm 4.22, \quad 8.03 \pm 1.3$ and $17.47 \pm 2.94$ respectively) with significant statistically difference.

Table (8): shows that the only significant independent factors associated with mortalities of neonates of respiratory distress were residence, causes of RD, birth weight and place of delivery. Rural, low birth weight and home delivery neonates were risky of mortalities than others.

Fig (1) shows that hyaline membrane disease was the most important cause of neonatal respiratory distress followed by pneumonia and transient tachypnea of the newborn .

\section{Discussion}

The present study revealed that RD constituted $52.9 \%$ of total admission. RD 
Table (3): Relationship between type, sex of neonates and causes of RD among admitted neonates to NICU of Assiut University Children Hospital,2014.

\begin{tabular}{|c|c|c|c|c|}
\hline \multirow[b]{2}{*}{ Causes of RD } & \multicolumn{2}{|c|}{ Type of the neonate ( $\%$ from rows) } & \multirow{2}{*}{$\begin{array}{c}\text { Total } \\
(\mathrm{N}=\mathbf{4 8 7})\end{array}$} & \multirow[b]{2}{*}{ P-value } \\
\hline & $\begin{array}{c}\text { Single (368) } \\
\text { N }(\%)\end{array}$ & $\begin{array}{c}\text { Multiple (119) } \\
\text { N (\%) } \\
\end{array}$ & & \\
\hline Hyaline membrane disease & $137(61.4)$ & $86(38.6)$ & 223 & $<0.0001$ \\
\hline Transient tachypnea of the newborn & $76(91.6)$ & $7(8.4)$ & 83 & $<0.0001$ \\
\hline Meconium aspiration syndrome & $9(100.0)$ & $0(0.0)$ & 9 & 0.122 \\
\hline Pneumonia & $68(79.1)$ & $18(20.9)$ & 86 & 0.40 \\
\hline Persistent pulmonary hypertension & $31(91.2)$ & $3(8.8)$ & 34 & 0.03 \\
\hline Congenital anomalies & $47(90.4)$ & $5(9.6)$ & 52 & 0.009 \\
\hline \multirow[b]{2}{*}{ Causes of RD } & \multicolumn{2}{|c|}{ Sex (\% from rows) } & \multirow{2}{*}{$\begin{array}{c}\text { Total } \\
(\mathrm{N}=487)\end{array}$} & \multirow[b]{2}{*}{ P-value } \\
\hline & $\begin{array}{c}\text { Male (263) } \\
\text { N (\%) } \\
\end{array}$ & $\begin{array}{c}\text { Female (224) } \\
\text { N (\%) }\end{array}$ & & \\
\hline Hyaline membrane disease & $119(53.4)$ & $104(46.6)$ & 223 & 0.6 \\
\hline Transient tachypnea of the newborn & $45(54.2)$ & $38(45.8)$ & 83 & 0.9 \\
\hline Meconium aspiration syndrome & $9(100.0)$ & $0(0.0)$ & 9 & 0.020 \\
\hline Pneumonia & $47(54.7)$ & $39(45.3)$ & 86 & 0.9 \\
\hline Persistent pulmonary hypertension & $12(35.3)$ & $22(64.7)$ & 34 & 0.07 \\
\hline Congenital anomalies & $31(59.6)$ & $21(39.4)$ & 52 & 0.009 \\
\hline
\end{tabular}

Chi square $\left(\chi^{2}\right)$ test was used, $\square$ Fisher's exact test.

Table (4): Relationship between gravidity, method of delivery and Causes of RDS among admitted neonates in NICU of Assiut University Children Hospital, 2014.

\begin{tabular}{|c|c|c|c|c|}
\hline \multirow[b]{2}{*}{ Causes of RD } & \multicolumn{2}{|c|}{ Gravidity (\% from rows) } & \multirow[b]{2}{*}{$\begin{array}{c}\text { Total } \\
(\mathbf{N}=\mathbf{4 8 7})\end{array}$} & \multirow[b]{2}{*}{ P-value } \\
\hline & $\begin{array}{c}\text { Primi-Gravid (129) } \\
\text { N (\%) }\end{array}$ & $\begin{array}{c}\text { Multigravida (358) } \\
\text { N (\%) }\end{array}$ & & \\
\hline Hyaline membrane disease & $74(33.2)$ & $149(66.8)$ & 223 & 0.002 \\
\hline Transient tachypnea of the newborn & $18(21.7)$ & $65(78.3)$ & 83 & 0.3 \\
\hline Meconium aspiration syndrome & $4(44.4)$ & $5(55.6)$ & 9 & 0.2 \\
\hline Pneumonia & $22(25.6)$ & $64(74.4)$ & 86 & 0.8 \\
\hline Persistent pulmonary hypertension & $8(23.5)$ & $26(76.5)$ & 34 & 0.7 \\
\hline Congenital anomalies & $3(5.8)$ & $49(94.2)$ & 52 & $<0.0001$ \\
\hline \multirow[b]{2}{*}{ Causes of RD } & \multicolumn{2}{|c|}{ Method of delivery ( $\%$ from rows) } & \multirow{2}{*}{$\begin{array}{c}\text { Total } \\
(\mathrm{N}=487)\end{array}$} & \multirow[b]{2}{*}{ P-value } \\
\hline & $\begin{array}{c}\text { Normal (164) } \\
\text { N (\%) }\end{array}$ & $\begin{array}{c}\text { Cesarean (323) } \\
\text { N }(\%)\end{array}$ & & \\
\hline Hyaline membrane disease & $78(35.0)$ & $145(65.0)$ & 223 & 0.6 \\
\hline Transient tachypnea of the newborn & $28(33.7)$ & $55(66.3)$ & 83 & 0.9 \\
\hline Meconium aspiration syndrome & $4(44.4)$ & $5(55.6)$ & 9 & 0.4 \\
\hline Pneumonia & $32(37.2)$ & $54(62.8)$ & 86 & 0.4 \\
\hline Persistent pulmonary hypertension & $11(32.3)$ & $23(67.7)$ & 34 & 0.9 \\
\hline Congenital anomalies & $11(21.2)$ & $41(78.8)$ & 52 & 0.04 \\
\hline
\end{tabular}

Chi square $\left(\chi^{2}\right)$ test was used, $\square$ Fisher's exact test. represented $41.03 \%$ of admission in Special Care Baby Unit (SCBU) at Gharian Teaching Hospital. ${ }^{11}$

Mohamed et al revealed that respiratory distress was the commonest primary diagnosis (94.5\%) among all admitted neonates, to neonatal intensive care unit in pediatric Assiut University Hospital. ${ }^{12}$

On the other hand the incidence of neonates with respiratory distress was $(33.3 \%)$ in Neonatal Intensive Care Unit, National Institute of Child Health, Karachi. ${ }^{13}$

In addition, respiratory distress comprising $16.37 \%$ of all NICU admissions at kamla Nehru hospital, Gandhi medican 1 college, 
Table (5): Relationship between Hyaline membrane diseased neonates, treatment varieties, and their outcome in NICU of Assiut University Children Hospital, 2014.

\begin{tabular}{|c|c|c|c|c|}
\hline \multirow{2}{*}{ HMD } & \multicolumn{2}{|c|}{ Surfactant } & \multirow{2}{*}{ Total } & \multirow{2}{*}{$\begin{array}{c}\text { P- } \\
\text { value }\end{array}$} \\
\hline & $\begin{array}{l}\text { Yes } \\
\text { (33) }\end{array}$ & $\begin{array}{c}\text { No } \\
\text { (190) }\end{array}$ & & \\
\hline Recovery & $25(75.8)$ & $43(22.6)$ & $68(30.5)$ & \\
\hline Death & $8(24.2)$ & 147 (77.4) & $155(69.5)$ & $<0.001$ \\
\hline \multirow{2}{*}{ HMD } & \multicolumn{2}{|c|}{ CPAP } & \multirow{2}{*}{ Total } & \multirow{2}{*}{$\begin{array}{c}\text { P- } \\
\text { value }\end{array}$} \\
\hline & $\begin{array}{l}\text { Yes } \\
(42)\end{array}$ & $\begin{array}{c}\text { No } \\
\text { (181) }\end{array}$ & & \\
\hline Recovery & $28(66.7)$ & $40(22.1)$ & $68(30.5)$ & $<0001$ \\
\hline Death & $14(33.3)$ & 141(77.9) & $155(69.5)$ & \\
\hline \multirow[t]{2}{*}{ HMD } & \multicolumn{2}{|c|}{$\begin{array}{l}\text { Mechanical } \\
\text { ventilation }\end{array}$} & \multirow[t]{2}{*}{ Total } & \multirow{2}{*}{$\begin{array}{c}\text { P- } \\
\text { value }\end{array}$} \\
\hline & $\begin{array}{c}\text { Yes } \\
(140)\end{array}$ & $\begin{array}{l}\text { No } \\
(83)\end{array}$ & & \\
\hline \multirow{2}{*}{$\begin{array}{l}\text { Recovery } \\
\text { Death }\end{array}$} & $20(14.3)$ & $48(57.8)$ & $68(30.5)$ & \multirow{2}{*}{$<0.001$} \\
\hline & $120(85.7)$ & $35(42.2)$ & $155(69.5)$ & \\
\hline
\end{tabular}

HMD: Hyaline Membrane Disease CPAP: Continuous positive airway pressure.

Bhopal ${ }^{(14)}$ and Prasad etal ,2011 reported that RD constitutes $17 \%$ of common causes of morbidities. ${ }^{15}$

This study showed that hyaline membrane disease constituted $24.3 \%$ of total admission. A study was done in United States revealed that hyaline membrane disease was constituted $10.5 \%$ among neonates admitted to NICU. ${ }^{16}$ Knowledge of the causes of respiratorydistress is essential for planning and provision of basic services for sick neonates especially low birth weight. ${ }^{17}$

The study revealed that hyaline membrane disease was the most important cause of neonatal respiratory distress $(45.8 \%)$ followed by pneumonia and transient tachypnea of the newborn .This agree with a study that was done in Gharian Teaching Hospital. ${ }^{11}$ Parkash et al, 2015 documented that sepsis and pneumonia were the most common causes of respiratory distress in the neonates ( $18 \%$ each). ${ }^{18}$

On the other hand studies revealed that common causes of neonatal RD were transient tachypnea of newborns (TTN) and respiratory distress syndrome (RDS). 14,19 , and 20

Table (6): Fatality of different diseases that cause RD of admitted respiratory distress in NICU of Assiut University Children Hospital , 2014.

\begin{tabular}{lccc}
\hline $\begin{array}{l}\text { Diseases that } \\
\text { cause RD }\end{array}$ & $\begin{array}{c}\text { Deaths } \\
\text { (276) }\end{array}$ & Cases & \% \\
\hline $\begin{array}{l}\text { Hyaline } \\
\text { membrane } \\
\text { disease }\end{array}$ & 155 & 223 & 69.5 \\
$\begin{array}{l}\text { Transient } \\
\text { tachypnea of } \\
\text { the newborn }\end{array}$ & 0 & 83 & 0 \\
$\begin{array}{l}\text { Meconium } \\
\text { aspiration }\end{array}$ & 6 & 9 & 66.7 \\
$\begin{array}{l}\text { syndrome } \\
\text { Pneumonia }\end{array}$ & 48 & 86 & 55.8 \\
$\begin{array}{l}\text { Persistent } \\
\text { pulmonary } \\
\text { hypertension }\end{array}$ & 31 & 34 & 91.2 \\
$\begin{array}{l}\text { Congenital } \\
\text { anomalies }\end{array}$ & 36 & 52 & 69.2 \\
\hline
\end{tabular}

Case Fatality Rate $(\mathrm{CFR})=($ No. of deaths due to certain disease/ Total cases from that disease) x100 (10).

This result documented that majority of cases of hyaline membrane disease were preterm and low birth weight with statistical significant difference this is conformed to finding from many studies. ${ }^{12,21,22,23}$ Ghafoor et al, 2003 reported that RDS is the commonest cause of respiratory distress in the preterm infants. ${ }^{8}$ Zhang et al,2015 pointed to that $50 \%$ of RDS neonates were preterm. ${ }^{24}$ Caner et al. 2015 indicated the incidence of RDS was $40.6 \%$ among premature infants who were admitted to the neonatal intensive care unit. ${ }^{25}$ This result revealed that slightly more than half of cases of transient tachypnoea of newborn were preterm and low birth weight with statistical significant difference this agreed with many studies. ${ }^{8,22}$ Furthermore, the present study reported that high mortality rate $(56.7 \%)$ compared to other studies reporting mortality at NICUs. This may be contributed to higher percentages of preterm and LBW which are the commonest neonatal mortality. In addition to our study 
Table (7): Survival analysis of different causes of RDS of admitted neonates in NICU of Assiut University Children Hospital ,2014.

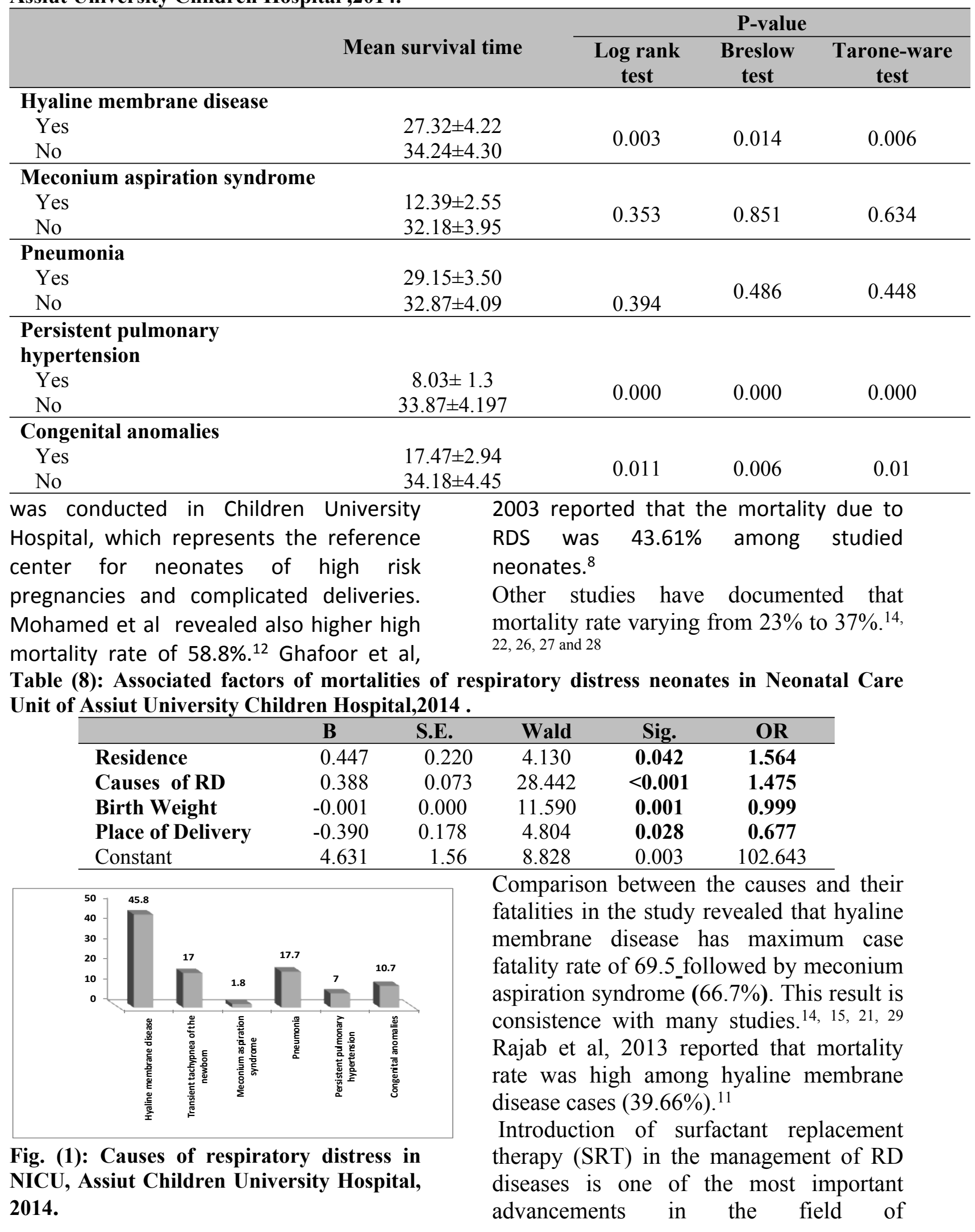


neonatology. ${ }^{30}$ The present study documented that $75.8 \%$ of hyaline membrane diseased neonates who treated by surfactant were cured with significant statistical difference .This result agree with Sanka et al,2016 which revealed SRT is an effective, and feasible management that cause a significant reduction in neonatal mortality of preterm with respiratory distress. ${ }^{31}$

Steven et al, 2007 revealed that surfactant therapy decreased mortality rate of respiratory distress syndrome by just about $50 \% .{ }^{32}$

This study showed that correlates of neonatal mortality were causes of $\mathrm{RD}$, birth weight, type of neonates either single or, multiple and residence. Mohamed et al revealed that the associated risk factors of neonatal mortality in NICU were respiratory distress, twin pregnancy and low birth weight. ${ }^{12}$

\section{Conclusion}

Hyaline membrane disease, TTN, pneumonia, MAS were important causes of neonatal RD in this study. Preterm and low birth weights were common risk of hyaline membrane disease and TT. Hyaline membrane disease followed by MAS had highest case fatality rate. Causes of RD, birth weight, residence and place of delivery were correlates of neonatal mortality.

\section{Recommendation}

The findings of the present study suggest that development of strategies aiming to reduction of $\mathrm{RD}$ among neonates through proper antenatal care to decrease the incidence of premature labor, evaluation of indication of cesarean section encourage hospital delivery. Furthermore, surveillance programs for neonatal mortality should include preventive measures and interventions for better natal care and postnatal care. Finally, improvement of health services quality in the NICU

\section{References .}

1. Oestergaard , M. Z., Inoue, M., Yosgida, S., Mahanani, W. R., Gore, F. M., Cousens, S., Lawn, J. E. \& Mathers, C. D. (2011): Neonatal mortality levels for 193 countries in 2009 with trends since 1990: a systematic analysis of progress, projections, and priorities. PLoS medicine, 8, e1001080.

1. Stoll, B. J. \& Measham, A. R. (2001): Children can't wait: improving the future for the world's poorest infants. The Journal of Pediatrics, 139, 729-733.

2. Morris, I. \& Adappa, R. (2012): Minimizing the risk of respiratory distress syndrome. Paediatrics and Child Health, 22, 513-517.

3. Hermansen, C. L. \& Lorah, K. N.( 2007): Respiratory distress in the newborn. American family physician, 76 .

4. Hammeed, N. N., AL-Janabi, M. K. \& AL-Reda, Y. I. (2007): Respiratory Distress in Full Term Newborns. THE IRAQI POSTGRADUATE MEDICAL JOURNAL, 6 .

5. Kamath, B. D., Macguire, E. R., Mcclure, E. M., Goldenberg, R. L. \& Jobe, A. H.( 2011):Neonatal mortality from respiratory distress syndrome: lessons for low-resource countries. Pediatrics, 127, 1139-1146.

6. Seoud, I., EL-Din, R. M. G., Said, R. N. \& Hessin, H. A. (2005): Predictors of Neonatal Mortality in Intensive Care Unit in Children's Hospital, Cairo University. Alexandria Journal of Pediatrics, 19, 93.

7. Saeed Zaman, Lutufullah Goheer and Hassan Riaz (2013):Prevalence and etiology of respiratory distress in neoborns . vol63,no. 1,

8. Suzanne Reuter, MD, Chuanpit Moser, MD and Michelle Baack, D(2014): 
Respiratory Distress in the Newborn Pediatr Rev. Oct; 35(10): 417-429.

9. Bhalwar, R., Vaidya, R., Tilak, R., Gupta, R. \& Kunte, R.( 2009): Text book of public health and community medicine, New Delhi, India, Department of community medicine, Armed forces medical college,Pune,WHO, India office , New Delhi.

10. Rajab A. M .and .Ghareba A. M.( 2013): Neonatal Mortality Rate in the Special Care Baby Unit (SCBU) at Gharian Teaching Hospital. Journal of Medical Science and Clinical Research. Volume||1||Issue||5||Pages195-208.

11. Mohamed E. M., Soliman A. M. A. and El-Asheer O. M.(2011): Predictors of mortality among neonates admitted to neonatal intensive care unit in pediatric Assiut +University Hospital, Egypt. Journal of American Science;7(6)
12. Parkash
A, Haider
N, Khoso

ZAand Shaikh

AS.(2015):Frequency, causes and outcome of neonates with respiratory distress admitted to Neonatal Intensive Care Unit, National Institute of Child Health, Karachi. J Pak Med Assoc. 1;65(7):771-5.

13. Swarnkar K and Swarnkar M(2015):Neonatal respiratory distress in early neonatal period and its outcome. International Journal of Biomedical and Advance Research 2015; 6(09): 643-647. 643

14. Prasad V, and Singh N(2011 ):Causes of morbidity and mortality in neonates admitted in Government Medical College Haldwaniin Kumaun Region (Uttrakhand) India JPBMS .volume 8 .Issnno-22307885.

15. Judith U. Hibbard,etal (2010) :Respiratory Morbidity in Late Preterm Births. JAMA.; 304(4):419-425.

16. Khatua S, Gangwal A, Basu P, Palodhi P(1979): The incidence and etiology of respiratory distress in newborn. Indian pediatrics.;16(12):1121.

17. Parkash A, KhosoZA . Haider N . Shaikh A S (2015): Frequency, causes and outcome of neonates with respiratory distress admitted to Neonatal Intensive Care Unit, National Institute of Child Health, Karachi. J Pak Med Assoc. Jul;(7):771-5

18. Hermansen CL, Lorah $\mathrm{KN}(2007)$ : Respiratory distress in the newborn. American family physician, 2007; 76,987994.

19. Hameed N N , Al-Janabi M K and AL-Reda YI(2007): Respiratory Distress in Full Term Newborns. The Iraqi Postgraduate Medical Journal. Vol.6, No. 3.

20. Swarnkar K and Swarnkar M( 2015): Neonatal respiratory distress in early neonatal period and its outcome. International Journal of Biomedical and Advance Research; 6(09): 643-47.

21. Dani C., Reali M.F., Bertini G., Wiechmann L., Spagnolo A., Tangucci M.and Rubaltelli F.F(1999): Risk factors for the development of respiratory distress syndrome and transient tachypnoea in newborn infants. ERS Journals Ltd. ISSN 0903-1936.

22. Fehlmann E, Tapia JL, Fernández R, Bancalari A, Fabres J, D'Apremont I, García-Zattera MJ, Grandi C, Ceriani Cernadas JM and Grupo Colaborativo Neocosur(2010):Impact of respiratory distress syndrome in very low birth weight infants: a multicenter South-American study.Arch Argent Pediatr,108(5):393-400. 23. Zhang, L., Cao, H., Zhao, S., Yuan, L., Han, D., Jiang, H. and EI, A.L. (2015): Effect of Exogenous Pulmonary Surfactants on Mortality Rate in Neonatal Respiratory Distress Syndrome: A Network Meta-Analysis of Randomized Controlled Trials. Pulmonary Pharmacology \& Therapeutics. In Press, 
Accepted Manuscript, Available Online 18 August 2015.

24. Caner, I., Tekgunduz, K.S., Temuroglu, A., Demirelli, Y. and Kara, M. (2015): Evaluation of Premature Infants Hospitalized in Neonatal Intensive Care Unit between 2010-2012. The Eurasian Journal of Medicine, 47, 1320.http://dx.doi.org/10.5152/eajm.2014.38

25. Brito AS, Matsuo T, Gonzalez MR, de Carvalho AB, Ferrari LS. (2003): (CRIB score, birth weight and gestational age in neonatal mortality risk evaluation). Rev Saude Publica; 37: 597-602.

26. Lemons JA, Bauer CR, Oh W, et al. (2001): Very low birth weight outcomes of the National Institute of Child health and human development neonatal research network, January 1995 through December 1996. NICHD Neonatal Research Network. Pediatrics; 107: E1.

27. Vasudevan A, Malhotra A, Lodha R, Kabra SK. (2006): Profile of neonates admitted in pediatric ICU and validation of score for neonatal acute physiology (SNAP). Indian Pediatrics; 43: 344 - 348. 28. Islam A.K.S., Bora R., Paul N and Ramasamy S(2016): Pattern of Respiratory Problems in Neonates in a
Level III Neonatal Care Unit with Special Reference to Pneumonia. Indian Journal of Neonatal Medicine and Research. Vol4(4): PO01-PO05

29. Flores-Nava G, López-Padilla M, Barrera-Millán E, Escobedo-Chávez E, Thompson-Chagoyan O, Humberto JR(1995): Ensayo clínico con un surfactante artificial para el tratamiento del síndrome de dificultad respiratoria neonatal. Perinatol Reprod Hum; 9(3): 149-155

30. Sankar M J, Gupta N, Jain $\mathrm{K}$, Agarwal $\mathrm{R}$ and Paul V $\mathrm{K}(2016)$ :Efficacy and safety of surfactant replacement therapy for preterm neonates with respiratory distress syndrome in lowand middle-income countries: a systematic review. Journal of Perinatology (2016) 36, S36-S48. doi:10.1038/jp..31

31. Stevens TP, Harrington E, Blennow M, Soll R (2007): Early surfactant administration with brief ventilation vs. selective surfactant and continued mechanical ventilation for preterm infants with or at risk for respiratory distress syndrome. Cochrane Database Syst Rev.; 4 (4). 